\title{
ENRAIZAMENTO DE ESTACAS DE NOVE CULTIVARES DE Vitis rotundifolia NA PRIMAVERA E VERÃO TRATADAS COM ÁCIDO INDOL BUTÍRICO ${ }^{1}$
}

\section{ROOTING OF INDOLE-3-BUTYRIC ACID-TREATED CUTTINGS OF NINE Vitis rotundifolia CULTIVARS PERFORMED DURING SPRING AND SUMMER}

\author{
Sérgio DENEGA ${ }^{2}$ \\ Luiz Antonio $\mathrm{BIASI}^{3}$ \\ Flávio ZANETTE ${ }^{3}$ \\ Ildon Rodrigues do NASCIMENTO 4 \\ Sirlei Janine BLASKEVICZ ${ }^{5}$
}

\begin{abstract}
RESUMO
Este trabalho objetivou avaliar o enraizamento de nove cultivares de Vitis rotundifolia utilizando-se as concentrações de $0,500,1000$ e $2000 \mathrm{mg} \mathrm{dm}^{-3}$ de ácido indol butírico (AIB), na primavera e no verão de 2005. 0 delineamento utilizado nas duas épocas do ano foi inteiramente casualizado com nove tratamentos, dez estacas por parcela e quatro repetições. As cultivares estudadas foram: Topsail, Magnolia, Creek, Noble, Roanoke, Magoon, Regale, Bontiful e Dixie, sendo a estaquia realizada em câmara de nebulização intermitente. Após 75 dias, em ambos experimentos, avaliaramse as variáveis porcentagem de estacas com folha retida; porcentagem de estacas mortas; porcentagem de estacas enraizadas; número médio de raízes primárias por estaca; comprimento médio das raízes primárias por estaca, massa fresca e seca das raízes por estaca. No verão a maior porcentagem das estacas que retiveram suas folhas foram aquelas que não receberam tratamento com AIB. A porcentagem de estacas mortas aumentou proporcionalmente com o aumento das concentrações de AIB e o comprimento das raízes diminuiu. Na primavera, com o aumento das concentrações de AIB, a porcentagem de estacas com folhas e de estacas enraizadas diminuiram, e a porcentagem de estacas mortas e a massa fresca aumentaram, mas com a concentração de $2000 \mathrm{mg} \mathrm{dm}^{-3}$ a massa fresca diminuiu bruscamente. Conclui-se que o AIB não aumentou o enraizamento das estacas, chegando a diminuir em diversas cultivares, não sendo recomendada a sua utilização na estaquia de Vitis rotundifolia.
\end{abstract}

Palavras-chave: estaquia; auxina; videira.

\begin{abstract}
The goal of this experiment was to evaluate rooting on cuttings of nine Vitis rotundifolia cultivars treated with four indole-3-butyric acid (IBA) concentrations $\left(0,500,1000\right.$ and $\left.2000 \mathrm{mg} \mathrm{dm}^{-3}\right)$ in the spring and summer of 2006. A completely random design with nine treatments, 10 cuttings per parcel and four replications was used in both seasons, separately. Cuttings of Topsail, Magnolia, Creek, Noble, Roanoke, Magoon, Regale, Bontiful and Dixie were placed under intermittent mist. Both experiments were evaluated 75 days after implantation being the following variables evaluated: percentage of cuttings having leaf retention; percentage of dead cuttings; percentage of rooted cuttings; number of primary roots per cutting; average length of primary roots per cutting $(\mathrm{cm})$, fresh and dry matter of roots per cutting $(\mathrm{mg})$. In the summer, the greatest percentages of cuttings retaining their leaves were the non-IBA-treated ones. The percentage of dead cuttings increased however the length of roots was inversely related to IBA concentration. In the spring, the percentage of cuttings retaining leaves and percentage of rooted cuttings were inversely related to IBA concentration, the percentage of dead cuttings and fresh matter of roots increased, but with $2000 \mathrm{mg} \mathrm{dm}^{-3}$ the fresh matter diminished abruptly. It was possible to conclude that IBA did not improve rooting of the cuttings as it diminished rooting in many of the cultivars tested herein and its application it is not recommended for cutting propagation of Vitis rotundifolia.
\end{abstract}

Key-words: cutting propagation; auxin; vines.

\footnotetext{
1 Parte da Tese de Doutorado do primeiro autor apresentada ao Programa de Pós-graduação em Agronomia - Produção Vegetal da Universidade Federal do Paraná (UFPR). Curitiba-PR.

${ }^{2}$ Engenheiro Agrônomo, Dr., Economista. Departamento de Agronomia, Universidade Estadual do Centro-Oeste (UNICENTRO). Rua Simeão Camargo Varela de Sá, n. 03, Bairro Cascavel, CEP 85.040-080, Guarapuava-PR, Brasil. E-mail: sdenega@unicentro.br. Autor para correspondência.

${ }^{3}$ Engenheiro Agrônomo, Dr. Professor. Departamento de Fitotecnia e Fitossanitarismo. Universidade Federal do Paraná. Caixa Postal 19061. CEP 81.531.990. Curitiba-PR, Brasil. Bolsista de Produtividade em Pesquisa do CNPq. E-mail: flazan@ufpr.br; biasi@ufpr.br.

${ }^{4}$ Engenheiro Agrônomo, Dr. Professor Adjunto. Departamento de Agronomia, Universidade Estadual do Centro-Oeste . Guarapuava-PR, Brasil. E-mail: nascimento_ildon@yahoo.com.br.

${ }^{5}$ Aluna do Curso de Agronomia da Universidade Federal do Paraná , Bolsista de Iniciação Científica do CNPq. Curitiba-PR, Brasil. E-mail: sblas@ufpr.br
} 


\section{INTRODUÇÃO}

A videira, uma das espécies frutíferas mais antigas cultivadas pelo homem, é propagada por estaquia (Sousa, 1996). Os principais reguladores vegetais utilizados para induzir o enraizamento de estacas são as auxinas, com destaque para o ácido indol butírico (AIB) e o ácido naftaleno acético (ANA). O AIB é provavelmente o melhor regulador de uso geral, sendo menos tóxico que o ANA para a maioria das plantas, mesmo em altas concentrações, e é bastante efetivo para um grande número de espécies (Hartmann et al., 2002). As espécies de difícil enraizamento respondem melhor à aplicação exógena de reguladores vegetais do que aquelas cujas estacas enraizam facilmente. Entretanto, a auxina nem sempre é o fator limitante ao enraizamento (Pires \& Biasi, 2003). Na videira o ANA apresenta-se, em alguns casos, inferior ao AIB, chegando até mesmo a mostrar-se inibidor do enraizamento (Terra et al., 1981).

A espécie Vitis rotundifolia é resistente à maioria dos problemas fitossanitários que afetam a videira, à exceção de uma forma especial de podridão negra. É sensível ao óxido de cálcio e à carência de magnésio e possui difícil hibridação com espécies da seção Euvitis, devido à diferença no número cromossômico. Possui racemos pequenos, bagas médias ou grandes, em geral de cor marrom escuro, às vezes claras e bronzeadas. É utilizada em cultivo comercial nos Estados Unidos, em especial, nos Estados da Flórida, Geórgia, Carolina do Norte e do Sul, sendo originária dos bosques úmidos do Sul dos Estados Unidos (Queiroz-Voltan \& Pires, 2003).

As estacas utilizadas para a propagação de porta-enxertos são normalmente coletadas durante o período de repouso da videira, quando as plantas estão sem folhas e com ramos bem amadurecidos (Alley, 1980). Este tipo de estaca lenhosa apresenta bons resultados de enraizamento para a maioria dos porta-enxertos utilizados comercialmente (Sousa, 1996), quando oriundos das espécies Vitis riparia e Vitis rupestris, que apresentam fácil enraizamento (Williams \& Antcliff, 1984). Entretanto, na propagação de cultivares de videiras muscadíneas as estacas lenhosas apresentam grande dificuldade de enraizamento, mesmo com a utilização de reguladores vegetais. Goode Junior et al. (1982) obtiveram apenas $2 \%$ de enraizamento para a cultivar Cowart e $10 \%$ para a Hunt utilizando diversos tratamentos, o que levou os autores a não recomendar esse tipo de estaca para a propagação de cultivares de videiras muscadíneas.

A presença da folha nas estacas é muito importante onde juntamente com as gemas, constituem fontes de auxina que, após a produção, é translocada para a base das estacas (Hartmann et al., 2002). A contribuição das folhas no processo de enraizamento também é explicada pela continuação do processo de fotossíntese que leva à produção de carboidratos e sua acumulação na base das estacas (Reuveni \& Raviv, 1981).
A época do ano em que é realizada a estaquia, também é fator importante para o enraizamento de porta-enxertos. O efeito da época de estaquia está relacionado com a condição fisiológica da planta matriz e a lignificação dos ramos no momento de sua coleta (Hartmann et al., 2002), sendo freqüentemente observadas diferenças anuais no enraizamento devido a variações nestas características de um ano para outro.

Este trabalho teve por objetivo verificar a habilidade de enraizamento de estacas caulinares de nove cultivares de $V$. rotundifolia utilizando-se diferentes concentrações de AIB nas estações da primavera e do verão no Estado do Paraná.

\section{MATERIAL E MÉTODOS}

O material vegetal foi coletado da coleção de cultivares de $V$. rotundifolia, existente no Setor de Fruticultura da Estação Experimental do Canguiri da Universidade Federal do Paraná, situada a $25^{\circ} 25^{\prime} \mathrm{S}$ e $49^{\circ} 08^{\prime} \mathrm{O}$, altitude de $930 \mathrm{~m}$, município de Pinhais - PR.

O clima da região segundo a classificação de Köppen é do tipo $\mathrm{Cfb}$, tendo a temperatura média do mês mais frio inferior a $18^{\circ} \mathrm{C}$, com verões frescos, sendo que a média do mês mais quente fica abaixo de $22{ }^{\circ} \mathrm{C}$. Janeiro e fevereiro são os meses mais quentes e os mais frios são junho e julho. Não apresenta estação seca definida e há ocorrência de geadas severas e freqüentes. A precipitação anual varia entre 1400 a $1800 \mathrm{~mm}$ e os meses de abril e maio são os mais secos.

Os experimentos foram conduzidos em casa-de-vegetação do Departamento de Fitotecnia e Fitossanitarismo do Setor de Ciências Agrárias da Universidade Federal do Paraná.

O substrato empregado foi a vermiculita de textura média colocada em bandejas plásticas perfuradas com dimensões de $65 \times 44 \times 19 \mathrm{~cm}$, comportando quatro repetições em cada uma delas, e mantidas sob nebulização intermitente. A nebulização foi efetuada com o intervalo de rega de $15 \mathrm{~min}$ das 08:00 às 17:00 h, a cada hora das 17:00 às $23: 00 \mathrm{~h}$ e a cada $3 \mathrm{~h}$ das $23: 00$ às 08:00 $\mathrm{h}$. $\mathrm{O}$ tempo de rega foi de $15 \mathrm{~s}$.

O delineamento utilizado foi o inteiramente casualizado com quatro repetições e dez estacas por parcela, em esquema fatorial $(9 \times 4)$, envolvendo nove cultivares e quatro concentrações de AIB, totalizando 1.440 estacas. As cultivares de $V$. rotundifolia estudadas foram: Topsail, Magnolia, Creek, Noble, Roanoke, Magoon, Regale, Bontiful e Dixie. As concentrações de AIB testadas foram 0 , 500,1000 e $2000 \mathrm{mg} \mathrm{dm}^{-3}$.

O AIB foi aplicado diluído por imersão rápida de $15 \mathrm{~s}$, solução hidro-alcoólica $1: 1(\mathrm{v} / \mathrm{v})$, e essa solução também foi utilizada na testemunha. $O$ mesmo experimento foi instalado em duas épocas do ano, primavera e verão de 2005.

As estacas foram preparadas com $10 \mathrm{~cm}$ de comprimento, podendo ter uma ou mais gemas dependendo do comprimento dos entrenós, 
consistência semilenhosa e uma folha inteira na parte superior da estaca. Como foi padronizado o tamanho das estacas, o corte na base foi realizado independente da presença de gemas.

Após 75 dias da estaquia, as variáveis

avaliadas foram: porcentagem de estacas com folha retida; porcentagem de estacas mortas;

porcentagem de estacas enraizadas; número médio de raízes primárias por estaca; comprimento médio das raízes primárias por estaca $(\mathrm{cm})$, massa fresca e seca das raízes por estaca $(\mathrm{mg})$.

Os resultados obtidos foram analisados estatisticamente para verificar se atenderam os pressupostos de homocedasticidade (Teste de Bartlett) e de normalidade dos resíduos para realizar a análise de variância. Quando não atenderam os dados foram transformados para realizar a análise de variância. As médias dos tratamentos foram comparadas pelo teste de Tukey a $5 \%$ de probabilidade ou pela análise de regressão polinomial.

\section{RESULTADOS E DISCUSSÃO}

Para todas as variáveis analisadas da época de verão, não foram encontradas interações significativas entre as cultivares e concentrações de AIB, sendo esses fatores analisados de forma independente.

$\mathrm{Na}$ época do verão as cultivares Topsail, Creek e Bontiful foram superiores a Noble e Magnólia quando analisadas as estacas que retiveram suas folhas após 75 dias em casa-devegetação (Tabela 1). O aumento da concentração de AIB influenciou de forma negativa a porcentagem de estacas com folha (Figura 1), o que não é desejável, pois a presença da folha em estacas semilenhosas de porta-enxertos de videira é essencial para a formação de raízes adventícias (Bordin et al., 2005).

TABELA 1 - Porcentagem de estacas com folhas retidas, de estacas mortas e de estacas enraizadas de nove cultivares de Vitis rotundifolia avaliadas após 75 dias, no verão de 2005, tratadas com ácido indol butírico. Curitiba - PR, 2005.

\begin{tabular}{|c|c|c|c|c|c|}
\hline \multirow{2}{*}{$\begin{array}{l}\text { Cultivar } \\
\text { Topsail }\end{array}$} & \multicolumn{2}{|c|}{ Estacas com folha retida (\%) } & Estacas mortas (\%) & \multicolumn{2}{|c|}{ Estacas enraizadas (\%) } \\
\hline & 45,62 & $a^{1,2}$ & 39,38 & 15,00 & $a b^{1,2}$ \\
\hline Magnólia & 11,87 & de & 56,25 & 0,62 & c \\
\hline Roanoke & 16,25 & $c d$ & 50,63 & 8,13 & bc \\
\hline Magoon & 20,00 & bcd & 58,75 & 6,25 & $\mathrm{bc}$ \\
\hline Creek & 40,00 & $a b$ & 48,13 & 6,88 & bc \\
\hline Regale & 29,37 & abcd & 54,38 & 6,25 & $\mathrm{bc}$ \\
\hline Dixie & 25,00 & abcd & 56,25 & 5,00 & bc \\
\hline Noble & 0,00 & e & 58,13 & 3,75 & bc \\
\hline Bontiful & 37,50 & $a b c$ & 48,75 & 25,63 & a \\
\hline
\end{tabular}

C.V. $(\%)$

47,14

25,17

64,56

${ }^{1}$ Médias seguidas pela mesma letra não diferem significativamente pelo teste de Tukey a $5 \%$ de probabilidade.

${ }^{2}$ Dados originais transformados para análise em raiz quadrada de $Y+1$.

${ }^{3}$ Não significativo.

Para a porcentagem de estacas mortas não houve diferença significativa entre as cultivares (Tabela 1) e nem entre as concentrações de AIB (Figura 2). A mortalidade foi semelhante a encontrada por Mayer et al. (2006), que avaliaram a capacidade de enraizamento de estacas de quatro cultivares de Vitis sp. sem o uso de AIB, e obtiveram $35 \%$ de estacas mortas para a cultivar Topsail. Para a porcentagem de estacas enraizadas, a cultivar Magnólia apresentou a menor porcentagem de enraizamento, enquanto que as cultivares Bontiful e Topsail foram superiores às demais e não diferiram entre si (Tabela 1). O AIB não apresentou efeito significativo para 0 enraizamento das estacas (Figura 3). Harmon (1943) que realizou um estudo com aplicação do AIB em 31 porta-enxertos, obteve respostas muito variáveis e aumento no enraizamento de alguns, o que levou o autor a concluir que não houve efeito benéfico do uso de AIB na propagação comercial dos porta-enxertos de videira testados. 
DENEGA, S. et al. Enraizamento de estacas de nove cultivares...

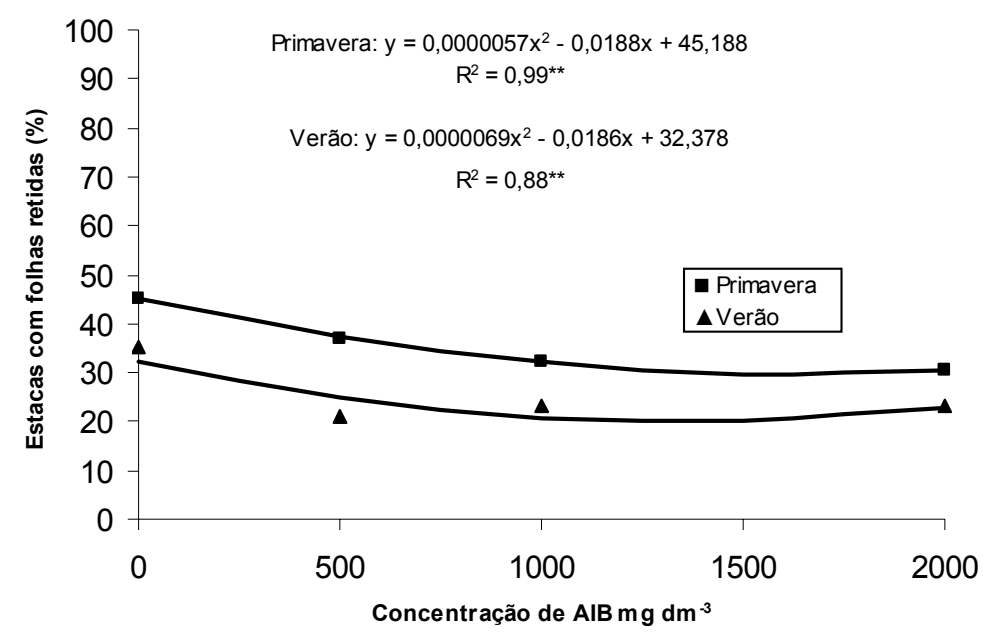

FIGURA 1 - Porcentagem de estacas com folha retida na primavera e no verão, de nove cultivares de Vitis rotundifolia tratadas com diferentes concentrações de ácido indol butírico, avaliadas após 75 dias.

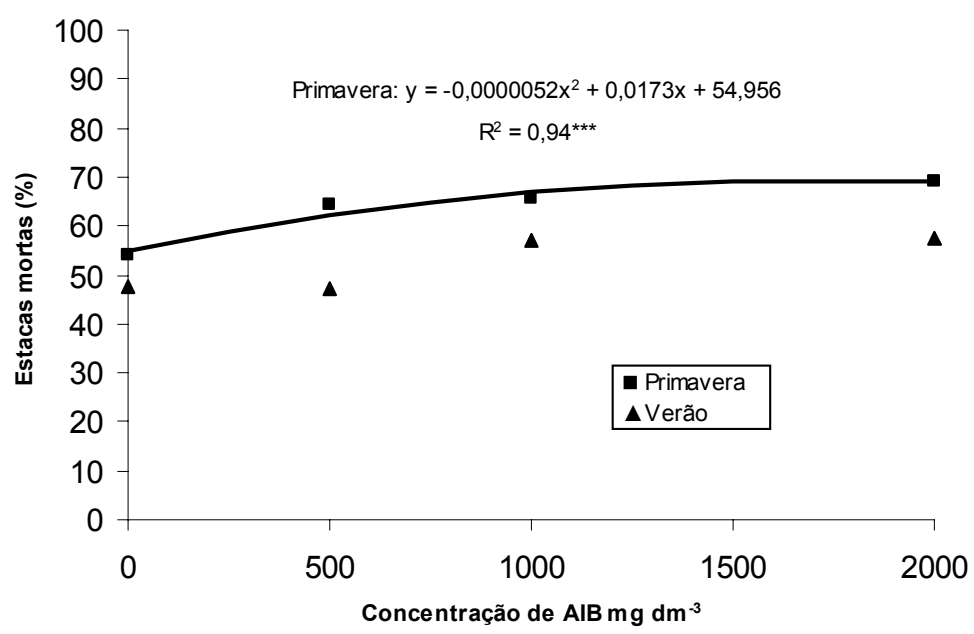

FIGURA 2 - Porcentagem de estacas mortas na primavera e no verão, de nove cultivares de Vitis rotundifolia tratadas com diferentes concentrações de ácido indol butírico, avaliadas após 75 dias. CuritibaPR. 2005. Diferenças não significativas no verão.

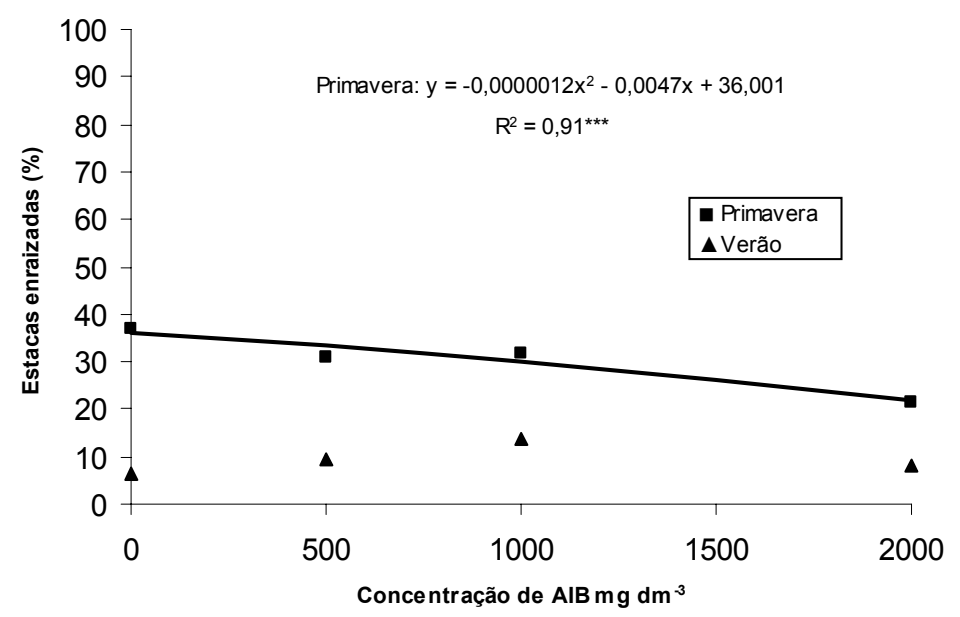

FIGURA 3 - Porcentagem de estacas enraizadas na primavera e no verão, de nove cultivares de Vitis rotundifolia tratadas com diferentes concentrações de ácido indol butírico, avaliadas após 75 dias. Curitiba-PR. 2005. Diferenças não significativas no verão. 
Pode-se constatar que houve um baixo enraizamento de estacas na época do verão, com a maioria das cultivares não atingindo $10 \%$ (Tabela 1) e não havendo influencia do AIB na formação de raízes (Figura 3). Esse resultado foi muito inferior ao obtido por Botelho et al. (2005a), que realizaram a estaquia herbácea em janeiro, do porta-enxerto VR043-43, híbrido entre V. vinifera e V. rotundifolia, e observaram $92 \%$ de enraizamento e $84 \%$ de brotação em estacas não tratadas com reguladores. Por outro lado, Mayer et al. (2006) constataram a dificuldade de enraizamento de estacas da espécie V. rotundifolia, sendo esta dificuldade atribuída a presença de barreiras anatômicas internas, identificadas como sendo calotas de fibras no floema primário e presença de floema secundário reduzido com faixas radiais de fibras.

Para o comprimento das raízes, destacaram-se as cultivares Bontiful, Topsail, Creek, Roanoke e Dixie que foram estatisticamente semelhantes entre si (Tabela 2). Não houve efeito da aplicação de AIB sobre o comprimento das raízes (Figura 4), com resultados semelhantes aos encontrados por Silva et al. (1986), que realizou um trabalho analisando 0 efeito do AIB no enraizamento de três porta-enxertos já enxertados de videira.

TABELA 2 - Comprimento, número, massa fresca e massa seca de raízes primárias emitidas por estaca de nove cultivares de Vitis rotundifolia avaliadas após 75 dias, no verão de 2005, tratadas com ácido indol butírico. Curitiba - PR, 2005.

\begin{tabular}{|c|c|c|c|c|c|c|c|c|}
\hline \multirow{2}{*}{$\begin{array}{l}\text { Cultivar } \\
\text { Topsail }\end{array}$} & \multicolumn{2}{|c|}{$\begin{array}{l}\text { Comprimento de } \\
\text { raízes }(\mathrm{cm})\end{array}$} & \multicolumn{2}{|c|}{$\begin{array}{c}\text { Número de raízes } \\
\text { por estaca }\end{array}$} & \multicolumn{2}{|c|}{$\begin{array}{l}\text { Massa fresca de } \\
\text { raízes por estaca } \\
(\mathrm{mg})\end{array}$} & \multicolumn{2}{|c|}{$\begin{array}{c}\text { Massa seca e raízes } \\
\text { por estaca }(\mathrm{mg})\end{array}$} \\
\hline & 3,93 & $a b^{1,2}$ & 1,94 & $a^{1,2}$ & 181,83 & $a b^{1,3}$ & 20,27 & $a b^{1,2}$ \\
\hline Magnólia & 0,28 & c & 0,13 & c & 8,94 & c & 0,75 & C \\
\hline Roanoke & 2,41 & $a b c$ & 0,91 & $a b c$ & 143,70 & $a b c$ & 12,91 & $a b c$ \\
\hline Magoon & 2,24 & $\mathrm{bc}$ & 0,47 & bc & 100,38 & bc & 9,25 & bc \\
\hline Creek & 3,06 & $a b c$ & 0,85 & $a b c$ & 152,95 & $a b c$ & 17,53 & $a b c$ \\
\hline Regale & 1,68 & bc & 0,88 & $a b c$ & 103,34 & bc & 9,50 & $\mathrm{bc}$ \\
\hline Dixie & 2,34 & $a b c$ & 0,13 & c & 116,60 & bc & 10,60 & $\mathrm{bc}$ \\
\hline Noble & 0,51 & $\mathrm{bc}$ & 0,50 & $a b c$ & 10,03 & bc & 0,38 & C \\
\hline Bontiful & 5,72 & a & 1,77 & $a b$ & 318,83 & $a$ & 31,55 & $a$ \\
\hline C.V. (\%) & 47, & & 31, & & & 83 & & 34,99 \\
\hline
\end{tabular}

${ }^{1}$ Médias seguidas pela mesma letra não diferem significativamente pelo teste de Tukey a $5 \%$ de probabilidade.

${ }^{2}$ Dados originais transformados para análise em raiz quadrada de $Y+1$.

${ }^{3}$ Dados originais transformados para análise em logaritmo base 10 de $\mathrm{Y}$.

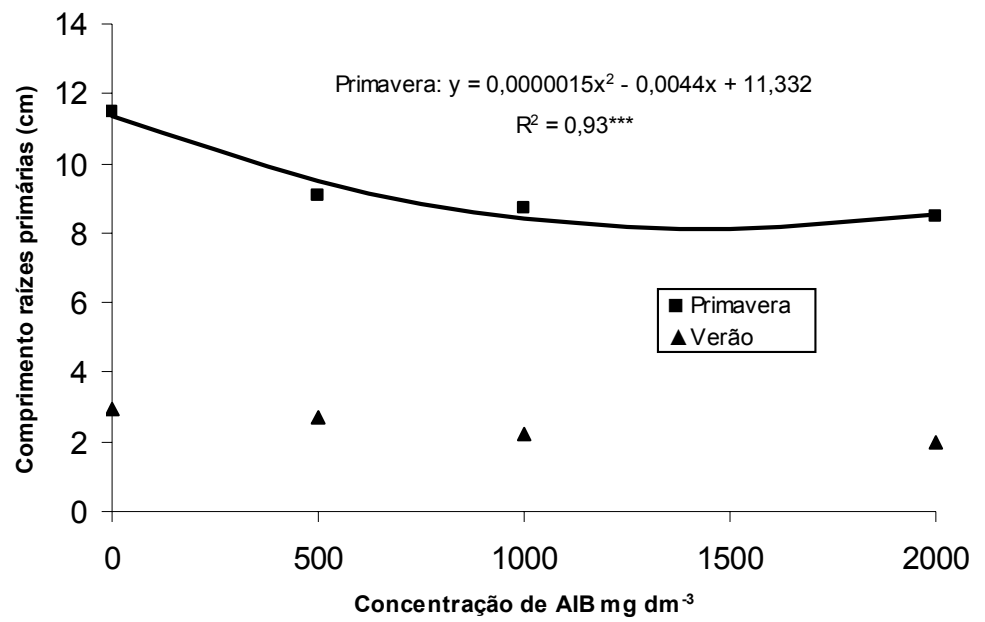

FIGURA 4 - Comprimento das raízes primárias $(\mathrm{cm})$ na primavera e no verão, de nove cultivares de Vitis rotundifolia tratadas com diferentes concentrações de ácido indol butírico, avaliadas após 75 dias. Curitiba-PR. 2005. Diferenças não significativas no verão. 
DENEGA, S. et al. Enraizamento de estacas de nove cultivares...

Para o número médio de raízes por estaca destacaram-se as cultivares Topsail, Bontiful, Roanoke, Regale, Creek e Noble (Tabela 2). O AIB também não apresentou efeito significativo. Botelho et al. (2005a), que avaliaram o enraizamento do híbrido VR-043-43, concluíram que utilizando-se AIB na concentração de $1000 \mathrm{mg} \mathrm{dm}^{-3}$ as estacas semilenhosas foram as que apresentaram maior porcentagem de enraizamento, propiciando também maior massa e número de raízes. Já Silva et al. (1986) obtiveram resultados superiores aos relatados acima, chegando a 26,12 raízes emitidas por estacas enxertadas em três cultivares de portaenxetos de videira.

Quanto a massa fresca e massa seca de raízes, a cultivar Bontiful foi superior as demais, mas não diferiu da Topsail, Creek e Roanoke (Tabela 2). A aplicação de AIB não apresentou efeito para a massa seca de raízes produzidas.
$\mathrm{Na}$ estaquia realizada na primavera, apenas houve interação significativa para a variável número médio de raízes por estaca, onde o efeito das concentrações de AIB foi analisado dentro de cada cultivar.

As cultivares Dixie, Regale, Roanoke, Bontiful, Topsail, Magoon e Magnólia foram estatisticamente semelhantes quando analisou-se as estacas que retiveram suas folhas após 75 dias da estaquia (Tabela 3 ). A permanência da folha nas estacas é importante como fonte de auxina e carboidratos, que são translocadas para a base das estacas estimulando o enraizamento (Reuveni \& Raviv, 1981; Hartmann et al., 2002). A retenção foliar decresceu com o aumento das concentrações de AIB (Figura 1) e as cultivares com maior retenção foliar apresentaram as maiores porcentagens de enraizamento, confirmando 0 efeito benéfico da presença das folhas.

TABELA 3 - Porcentagem de estacas com folhas retidas, de estacas mortas e de estacas enraizadas de nove cultivares de Vitis rotundifolia avaliadas após 75 dias, na primavera de 2005, tratadas com ácido indol butírico.Curitiba - PR, 2005.

\begin{tabular}{|c|c|c|c|c|c|c|}
\hline \multirow{2}{*}{$\frac{\text { Cultivar }}{\text { Topsail }}$} & \multicolumn{2}{|c|}{$\begin{array}{c}\text { Estacas com folha retida } \\
(\%)\end{array}$} & \multicolumn{2}{|c|}{ Estacas mortas (\%) } & \multicolumn{2}{|c|}{ Estacas enraizadas (\%) } \\
\hline & 37,50 & $a b^{1,3}$ & 61,25 & $a b c^{1,3}$ & 28,13 & $a b c^{1,2}$ \\
\hline Magnólia & 23,75 & $a b c$ & 73,13 & $a b$ & 25,00 & $a b c$ \\
\hline Roanoke & 45,63 & a & 54,38 & $a b c$ & 35,00 & $a b$ \\
\hline Magoon & 32,50 & $a b c$ & 66,25 & $a b c$ & 25,63 & $a b c$ \\
\hline Creek & 22,50 & bc & 76,88 & $a b c$ & 22,50 & $\mathrm{bc}$ \\
\hline Regale & 53,13 & a & 46,25 & C & 45,00 & a \\
\hline Dixie & 56,88 & a & 49,38 & bc & 43,75 & a \\
\hline Noble & 11,88 & c & 87,50 & a & 11,25 & $c$ \\
\hline Bontiful & 41,88 & a & 55,00 & $a b c$ & 36,25 & $a b$ \\
\hline C.V. $(\%)$ & \multicolumn{2}{|c|}{35,05} & \multicolumn{2}{|c|}{16,44} & \multicolumn{2}{|c|}{37,95} \\
\hline
\end{tabular}

${ }^{1}$ Médias seguidas pela mesma letra não diferem significativamente pelo teste de Tukey a $5 \%$ de probabilidade.

${ }^{2}$ Dados originais transformados para análise em raiz quadrada de $Y+1$.

${ }^{3}$ Dados originais transformados para análise em logaritmo base 10 de $\mathrm{Y}$.

Encontrou-se uma alta porcentagem de mortalidade de estacas, acima de $46 \%$, em todas as cultivares, chegando a $87,5 \%$ na cultivar Noble (Tabela 3). A porcentagem de estacas mortas foi maior com o aumento das concentrações de AIB (Figura 2). Esse efeito do AIB já foi observado no enraizamento de estacas semilenhosas do portaenxerto de videira 'VR043-43' (V. vinifera $x$ V. rotundifolia) (Machado et al., 2005).

Para a porcentagem de estacas enraizadas, as cultivares Regale e Dixie destacaram-se com as maiores taxas de enraizamento, e as cultivares Creek e Noble com as menores porcentagens, mas que foram semelhantes as maiores taxas obtidas no verão. $\mathrm{O}$
AIB foi prejudicial para o enraizamento, reduzindo a porcentagem de estacas enraizadas com 0 aumento das concentrações (Figura 3). Esse comportamento também foi observado com estacas herbáceas e semilenhosas do porta-enxerto de videira 'VR043-43', que apresentaram uma redução do enraizamento com o aumento da concentração de AIB até $3.000 \mathrm{mg} \mathrm{dm}^{-3}$ (Botelho et al., 2005b). Entretanto, estacas lenhosas desse mesmo portaenxerto responderam a aplicação de $3.000 \mathrm{mg} \mathrm{dm}^{-3}$ de $A I B$, enquanto as estacas não tratadas não enraizaram (Sozim \& Ayub, 2006). As cultivares de $V$. rotundifolia apresentam dificuldade em responder à aplicação de auxinas, conforme já relatado por Biasi \& Boszczowski (2005). Esses autores 
testaram o ANA e o AIB no enraizamento de estacas semilenhosas com uma folha das cultivares Magnólia e Topsail, e concluíram que a produção de mudas, nas condições estudadas por eles, pode ser obtida pela estaquia sem o uso de auxinas. Essa mesma recomendação também foi relatada para o híbrido 'VR043-43' (Machado et al., 2005).

Para a variável comprimento médio das raízes, a cultivar Regale foi superior a Creek e não diferiu das demais. O AIB reduziu o comprimento das raízes (Figura 4).

Para a massa fresca e seca, as cultivares Roanoke, Regale, Bontiful, e Topsail apresentaram as maiores médias (Tabela 4). A aplicação de AIB causou inicialmente o aumento na massa fresca das raízes emitidas por estaca até a concentração calculada de $763 \mathrm{mg} \mathrm{dm}^{-3}$ e a partir deste ponto começou uma redução (Figura 5 ). Em estacas lenhosas de quivizeiro, a aplicação de AIB até 8.000 $\mathrm{mg} \mathrm{dm}^{-3}$ promoveu aumento na massa seca de

TABELA 4 - Comprimento, massa fresca e massa seca de raízes emitidas por estaca de nove cultivares de Vitis rotundifolia avaliadas após 75 dias, na primavera de 2005, tratadas com ácido indol butírico. Curitiba - PR, 2005.

\begin{tabular}{|c|c|c|c|c|c|c|}
\hline \multirow{2}{*}{$\begin{array}{l}\text { Cultivar } \\
\text { Topsail }\end{array}$} & \multicolumn{2}{|c|}{ Comprimento de raízes $(\mathrm{cm})$} & \multicolumn{2}{|c|}{ Massa fresca $\left(\mathrm{mg} \mathrm{estaca}^{-1}\right)$} & \multicolumn{2}{|c|}{ Massa seca $\left(\mathrm{mg} \mathrm{estaca}^{-1}\right)$} \\
\hline & 10,24 & $a b^{1,2}$ & 314,98 & $a b^{1,3}$ & 53,75 & $a b c^{1,2}$ \\
\hline Magnólia & 8,14 & $a b$ & 142,05 & $a b$ & 40,78 & c \\
\hline Roanoke & 10,57 & $a b$ & 587,80 & a & 91,16 & a \\
\hline Magoon & 8,79 & $a b$ & 237,06 & $a b$ & 41,73 & $a b c$ \\
\hline Creek & 6,38 & $\mathrm{~b}$ & 299,63 & b & 51,50 & $\mathrm{bc}$ \\
\hline Regale & 12,97 & a & 465,03 & a & 82,32 & $a b$ \\
\hline Dixie & 8,21 & $a b$ & 207,03 & $a b$ & 30,86 & c \\
\hline Noble & 8,38 & $a b$ & 128,80 & $b$ & 17,63 & c \\
\hline Bontiful & 11,19 & $a b$ & 420,34 & a & 83,53 & $a b$ \\
\hline C.V. $(\%)$ & & & 43 & & & \\
\hline
\end{tabular}

${ }^{1}$ Médias seguidas pela mesma letra não diferem significativamente pelo teste de Tukey a $5 \%$ de probabilidade.

${ }^{2}$ Dados originais transformados para análise em raiz quadrada de $\mathrm{Y}+1$.

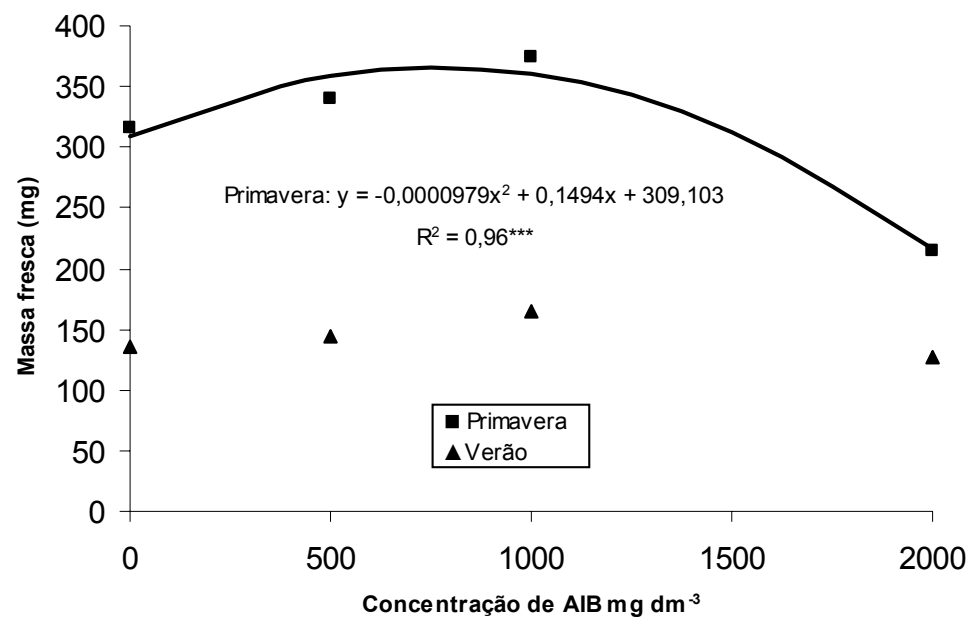

FIGURA 5 - Massa fresca (mg estaca ${ }^{-1}$ ) na primavera e no verão, de nove cultivares de Vitis rotundifolia tratadas com diferentes concentrações de ácido indol butírico, avaliadas após 75 dias. CuritibaPR. 2005. Diferenças não significativas no verão.

Como houve efeito da interação entre AIB e cultivar, o número médio de raízes emitidas por estaca apresentou um comportamento diferenciado entre as cultivares. Todas as cultivares apresentaram um comportamento quadrático para essa variável (Figura 6). As cultivares Creek, Magoon e Topsail apresentaram aumento do número de raízes com o aumento da concentração 
DENEGA, S. et al. Enraizamento de estacas de nove cultivares...

de AIB até as doses estimadas de 529, 750 e 777 $\mathrm{mg} \mathrm{dm}^{-3}$, respectivamente. Já as cultivares Roanoke, Regale, Bontiful e Dixie apresentaram aumento do número de raízes até concentrações maiores de AIB, estimadas de 1125, 1291, 1750 e $2083 \mathrm{mg} \mathrm{dm}^{-3}$, respectivamente. A cultivar Magnolia apresentou um comportamento diferenciado com tendência de aumentar o número de raízes com concentrações superiores a $2000 \mathrm{mg} \mathrm{dm}^{-3}$ de AIB, não sendo possível estimar o limite máximo dentro do intervalo de concentrações testado. Apenas a cultivar Noble reduziu a formação de raízes com o aumento da concentração de AIB.

\section{CONCLUSÕES}

Nas condições em que foi realizado o experimento para estaquia de $V$. rotundifolia, conclui-se não ser necessário uso do $\mathrm{AIB}$, e que a estaquia pode ser realizada com estacas semilenhosas com uma folha coletada na primavera.
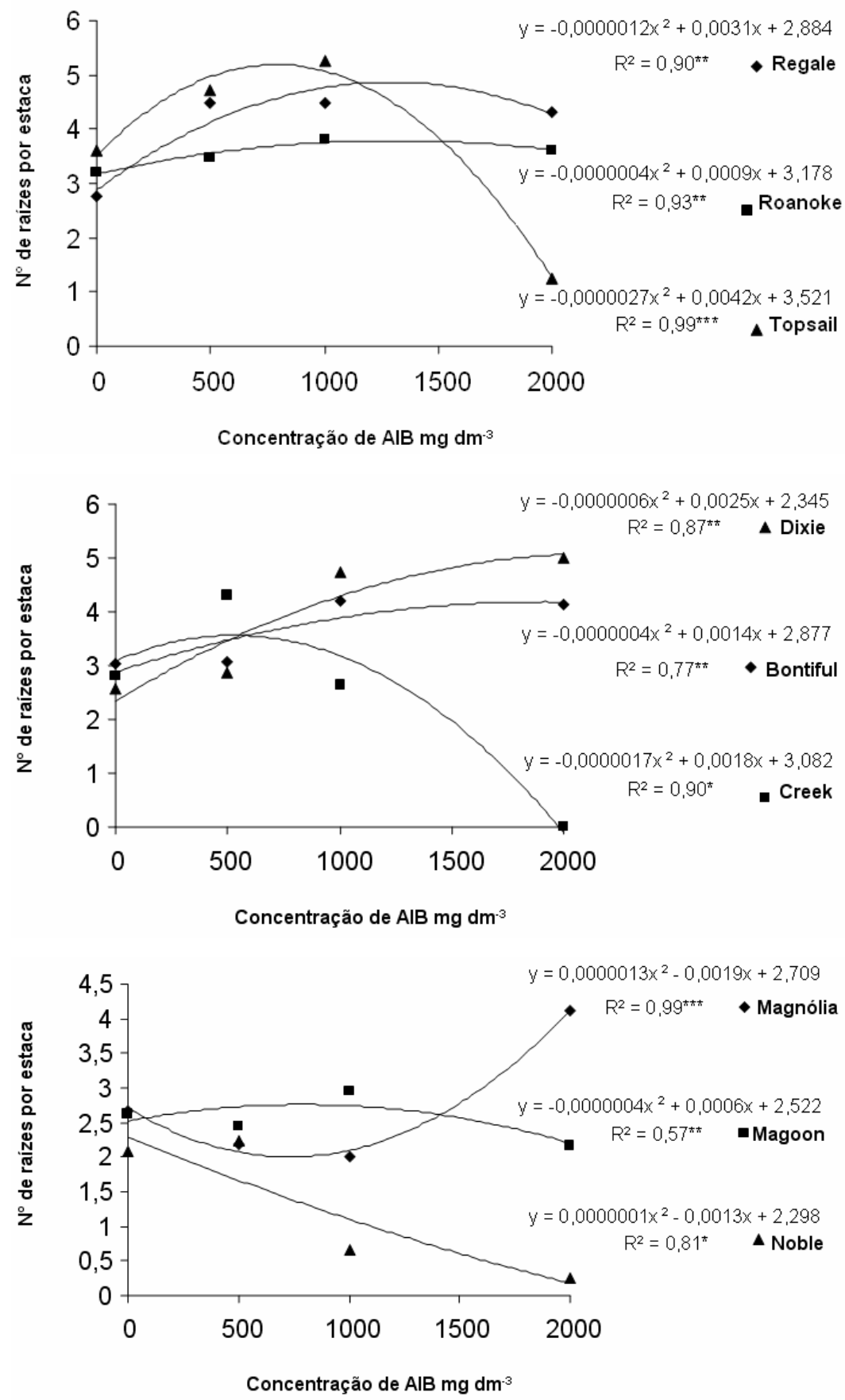

FIGURA 6 - Número de raízes por estaca na primavera, de nove cultivares de Vitis rotundifolia tratadas com diferentes concentrações de ácido indol butírico, avaliadas após 75 dias. Curitiba-PR. 2005. 


\section{REFERÊNCIAS}

1. ALLEY, C. J. Propagation of grapevines. California Agriculture, v. 34, n. 7, p. 29-30, 1980.

2. BIASI, L. A.; BOSZCZOWSKI, B. Propagação por estacas semilenhosas de Vitis rotundifolia cvs. Magnólia e Topsail. Revista Brasileira de Agrociência, v. 11, n. 4, p. 405-407, 2005.

3. BORDIN, I. et al. Efeito da presença da folha no enraizamento de estacas semilenhosas de porta-enxertos de videira. Ciência Rural, v. 35, n. 1, p. 215-218, 2005.

4. BOTELHO, R. V. et al. Efeito de reguladores vegetais na propagação vegetativa do porta-enxerto de videira '43-43' (Vitis vinifera $\times$ V. rotundifolia). Revista Brasileira de Fruticultura, v. 27, n. 1, p. 6-8, $2005 a$.

5. BOTELHO, R. V. et al. Estaquia do porta-enxerto de videira '43-43' (V. vinifera x V. rotundifolia) resistente à Eurhizococchus brasiliensis. Revista Brasileira de Fruticultura, v. 27, n. 3, p. 480-483, 2005b.

6. GOODE JUNIOR, D. Z. et al. Rooting studies of dormant muscadine grape cuttings. HortScience, v. 17, n. 4, p. 644-645, 1982.

7. HARMON, F. N. Influence of indolebutyric acid on the rooting of grape cuttings. Proceedings of the American Society for Horticultural Science, v. 42, p. 383-388, 1943.

8. HARTMANN, H. T.; KESTER, D. E.; DAVIES JUNIOR, F. T. Plant propagation: principles and practices. 7. ed. Englewood Cliffs: Prentice Hall, 2002. 880 p.

9. MACHADO, M. P. et al. Ácido indolbutírico no enraizamento de estacas semilenhosas do porta-enxerto de videira 'VR043-43' (Vitis vinifera $x$ Vitis rotundifolia). Revista Brasileira de Fruticultura, v. 27, n. 3, p. 476-479, 2005.

10. MANFROI, V. et al. Efeito do AIB sobre o enraizamento e desenvolvimento de estacas de quivi (Actinidia deliciosa). Ciência Rural, v. 27, n. 1, p. 43-45, 1997.

11. MAYER, J. L. S.; BIASI, L. A.; BONA, C. Capacidade de enraizamento de estacas de quatro cultivares de Vitis L. (Vitaceae) relacionada com os aspectos anatômicos. Acta Botanica Brasilica, v. 20, n. 3, p. 563-568, 2006.

12. PIRES, E. J. P.; BIASI, L. A. Propagação da videira. In: POMMER, C. V. (Ed.). Uva: tecnologia de produção, póscolheita, mercado. Porto Alegre: Cinco Continentes, 2003. p. 295-350.

13. QUEIROZ-VOLTAN, R. B.; PIRES, E. J. P. A videira. In: POMMER, C. V. (Ed.). Uva: tecnologia de produção, póscolheita, mercado. Porto Alegre: Cinco continentes, 2003. p. 37-61.

14. REUVENI, O.; RAVIV, M. Importance of leaf retention to rooting of avocado cuttings. Journal of the American Society for Horticultural Science, v. 106, n. 2, p. 127-130, 1981.

15. SILVA, A. L. da; FACHINELLO, J. C.; MACHADO, A. A. Efeito do ácido indolbutírico na enxertia e enraizamento da videira. Pesquisa Agropecuária Brasileira, v. 21, n. 8, p. 865-871, 1986.

16. SOUSA, J. S. I. de. Uvas para o Brasil. Piracicaba: FEALQ, 1996. 791 p.

17. SOZIM, M.; AYUB, R. A. Propagação de porta-enxertos de videira (Vitis sp.) submetidos ao tratamento com ácido indolbutírico. Publicatio UEPG - Ciências Exatas e da Terra, Ciências Agrárias e Engenharias, v. 12, n. 2, p. 37-41, 2006.

18. TERRA, M. M. et al. Efeitos de reguladores de crescimento no enraizamento de estacas de quatro porta-enxertos de videira. In: CONGRESSO BRASILEIRO DE FRUTICULTURA, 6., 1981, Recife. Anais... Recife: SBF, 1981. v. 4, p. 1265-1277.

19. WILLIAMS, P. L.; ANTCLIFF, A. J. Successful propagation of Vitis berlandieri and Vitis cinerea from hardwood cuttings. American Journal of Enology and Viticulture, v. 35, n. 2, p. 75-76, 1984.

Recebido em 26/08/2008 Aceito em 26/02/2009 
